\title{
Pengalaman ibu nifas terhadap budaya dalam perawatan masa nifas
}

\author{
Agustin Endriyani* \\ Program Studi Kebidanan Program Sarjana Terapan Fakultas IImu Kesehatan, Universitas \\ 'Aisyiyah Yogyakarta - Indonesia
}

\begin{abstract}
The influence of culture to the status of public health could not be ignored, health is an integral part of the culture. Ethnographic research results in health the year 2012 at 12 ethnics in Indonesia show the maternal and child health issues related to health culture is very concern. The purpose of this research is to know the experience of maternal childbirth to culture in the care period of parturition. This research was qualitative research with case studies. In-depth interview data collection methods (in-depth interview). Snowball sampling techniques. Participants in this research were the mother of the parturition is the working relic of clinics Paste. The number of participants that is used in this study is as much as 7 participants. The results of this research obtained 3 themes, namely, the knowledge of the participants towards parturition period care, influence the culture of the community, treatments against the time of parturition, and family support in the treatment period of parturition.
\end{abstract}

Keywords: care; culture; parturition

\begin{abstract}
Pengaruh budaya terhadap status kesehatan masyarakat tidak bisa diabaikan begitu saja, kesehatan merupakan bagian integral dari kebudayaan. Hasil riset etnografi kesehatan tahun 2012 di 12 etnis di Indonesia menunjukan masalah kesehatan ibu dan anak terkait budaya kesehatan sangat memprihatinkan. Tujuan dari penelitian ini untuk mengetahui pengalaman ibu nifas terhadap budaya dalam perawatan masa nifas. Penelitian ini adalah penelitian kualitatif dengan studi kasus. Metode pengumpulan data wawancara mendalam (indepth interview). Teknik snow ball sampling. Partisipan penelitian ini adalah ibu nifas yang berada diwilayah kerja Puskesmas Tempel. Jumlah partisipan yang digunakan dalam penelitian ini yaitu sebanyak 7 partisipan. Hasil dari penelitian ini didapatkan 3 tema yaitu, pengetahuan partisipan terhadap perawatan masa nifas, pengaruhnya budaya di masyarakat, terhadap perawatan masa nifas dan dukungan keluarga dalam perawatan masa nifas.
\end{abstract}

Kata Kunci: budaya; nifas; perawatan

*Korespondensi Penulis: Agustin Endriyani (email: endrisantosa@gmail.com), Jl. Ringroad Barat No. 63, Mlangi Nogotirto. Gamping, Kabupaten Sleman, Daerah Istimewa Yogyakarta 55592. 


\section{Pendahuluan}

Angka Kematian Ibu (AKI) merupakan salah satu indikator untuk melihat keberhasilan upaya kesehatan ibu. AKI adalah rasio kematian ibu selama masa kehamilan, persalinan dan nifas yang disebabkan oleh kehamilan, persalinan, dan nifas atau pengelolaannya tetapi bukan karena sebab-sebab lain seperti kecelakaan atau terjatuh di setiap 100.000 kelahiran hidup. Selain untuk menilai program kesehatan ibu, indikator ini juga mampu menilai derajat kesehatan masyarakat, karena sensitifitasnya terhadap perbaikan pelayanan kesehatan, baik dari sisi aksesibilitas maupun kualitas. Secara umum terjadi penurunan kematian ibu selama periode 1991-2015 dari 390 menjadi 305 per 100.000 kelahiran hidup. Walaupun terjadi kecenderungan penurunan angka kematian ibu, namun tidak berhasil mencapai target MDGs yang harus dicapai yaitu sebesar 102 per 100.000 kelahiran hidup pada tahun 2015. Hasil supas tahun 2015 memperlihatkan angka kematian ibu tiga kali lipat dibandingkan target MDGs (Pusdatin, 2018).

Angka kematian ibu dan angka kematian bayi merupakan indikator kesehatan reproduksi dimana di Indonesia masih tinggi dibandingkan dengan negara lain. Penelitian sebelumnya diketahui bahwa faktor budaya dan sosial demografi berpengaruh terhadap tingginya angka kematian ibu dan bayi (Suryawati, 2017).

Menyusui merupakan suatu proses alamiah, namun sering ibu-ibu tidak berhasil menyusui atau menghentikan menyusui lebih dini. Banyak alasan yang dikemukakan oleh ibu yang tidak menyusui anaknya, diantaranya ibu tidak mem- produksi ASI yang cukup. Masih banyak ibu menyusui yang melakukan pantangan makanan tertentu karena masih kuatnya tradisi tersebut di masyarakat. Hal tersebut yang menyebabkan ASI tidak berkualitas dan memenuhi kebutuhan bayi terutama dalam 6 bulan pertama (Yuliani, 2011).

Kepercayaan dan keyakinan budaya terhadap perawatan ibu post partum, masih banyak dijumpai dilingkungan masyarakat. Mereka meyakini budaya perawatan ibu setelah melahirkan dapat memberikan dampak yang positif dan menguntungkan bagi mereka. Hal ini terbukti dari penelitian yang dilakukan oleh Andhra Pradesh pada 100 orang ibu post partum di daerah Tirupati. Dari hasil penelitiannya didapatkan banyak kepercayaan dan keyakinan budaya perawatan ibu post partum, di antaranya pembatasan asupan cairan, makanan dibatasi dan hanya boleh makan sayur-sayuran, tidak boleh mandi, diet makanan, tidak boleh keluar rumah, menggunakan alas kaki, menggunakan gurita, tidak boleh tidur siang hari bahkan mereka meyakini kolostrum tidak baik untuk anak (Rahayu, Mudatsir, \& Hasballah, 2017).

Dari hasil penelitiannya didapatkan banyak kepercayaan dan keyakinan budaya perawatan ibu post partum, diantaranya pembatasan asupan cairan, makanan dibatasi dan hanya boleh makan sayur-sayuran, tidak boleh mandi, diet makanan, tidak boleh keluar rumah, menggunakan alas kaki, menggunakan gurita, tidak boleh tidur siang hari bahkan mereka meyakini kolostrum tidak baik untuk anak (Rahayu et al., 2017). 
Perkembangan sosial budaya dalam masyarakat merupakan suatu tanda bahwa masyarakat dalam suatu daerah tersebut telah mengalami suatu perubahan dalam proses berfikir. Perubahan sosial dan budaya bisa memberikan dampak positif maupun negatif. Hubungan antara budaya dan kesehatan sangatlah erat hubungannya, sebagai salah satu contoh suatu masyarakat desa yang sederhana dapat bertahan dengan cara pengobatan tertentu sesuai dengan tradisi mereka. Kebudayaan atau kultur dapat membentuk kebiasaan dan respons terhadap kesehatan dan penyakit dalam segala masyarakat tanpa memandang tingkatannya. Karena itulah penting bagi tenaga kesehatan untuk tidak hanya mempromosikan kesehatan, tapi juga membuat mereka mengerti tentang proses terjadinya suatu penyakit dan bagaimana meluruskan keyakinan atau budaya yang dianut hubungannya dengan kesehatan (Iqbal, Nurul, \& Iga, 2012).

\section{Metode Penelitian}

Rancangan penelitian yang digunakan adalah penelitian kualitatif dengan pendekatan studi kasus (Arikunto, 2013). Penelitian ini bermaksud untuk mengeksplorasi secara mendalam pengalaman ibu nifas terhadap budaya dalam perawatan masa nifas. Hasil penelitian ini disajikan dalam bentuk deskriptif naratif. Partisipan dalam penelitian ini yaitu ibu yang telah melahirkan, memungkinkan untuk diwawancarai (sehat) dan bersedia menjadi partisipan.

Pemilihan partisipan dilakukan secara snow ball sampling. Jumlah partisipan dalam penelitian ini adalah yaitu sebanyak 7 partisipan. Pencatatan data wawancara dilakukan menggunakan perekam suara setelah memperoleh persetujuan dari responden. Peneliti menggunakan pedoman wawancara ketika melakukan wawancara agar tidak ada pertanyaan yang tertinggal dan peneliti juga membawa catatan jika ada hal-penting yang harus dicatat. Pada saat melakukan penelitian proses wawancara dilakukan secara sadar, terarah dan senantiasa bertujuan memperoleh informasi yang diperlukan. Data yang dikumpuIkan dalam observasi berasal dari pengamatan tingkah laku responden dan pembicaraannya ringan serta santai. Adapun tahap proses analisis terhadap data yang diperoleh dalam penelitian ini menggunakan langkah Colizzi dalam Streubert \& Carpenter (Nursalam, 2008).

Keabsahan data (uji validasi) dalam penelitian ini dilakukan dengan teknik triangulasi. Dalam penelitian ini teknik triangulasi yang digunakan adalah triangulasi sumber. Penggunaan sumber sebagai triangulasi dengan cara membandingkan dan mengecek kembali data yang diperoleh dari partisipan kepada informan. Informan yang dimaksud adalah suami dan keluarga ibu nifas. Peneliti langsung melakukan triangulasi setelah mewawancari setiap partisipan agar tidak terjadi bias. Peneliti menggunakan ruang tamu. Selama wawancara informan memberikan informasi kepada peneliti secara terbuka sehingga peneliti memperoleh data sesuai yang dibutuhkan (Arikunto, 2013).

\section{Hasil dan Pembahasan}

Subyek penelitian atau partisipan pada penelitian ini diambil secara purposive sampling (partisipan penelitian dipilih berdasarkan tujuan atau kriteria tertentu yang telah ditetapkan sebe- 
Tabel 1.

Karakteristik Partisipan Berdasarkan Usia, Tingkat Pendidikan, Pekerjaan, dan Lama Menikah

\begin{tabular}{cllll}
\hline Partisipan & Usia & Obstetri & $\begin{array}{l}\text { Tingkat } \\
\text { Pendidikan }\end{array}$ & Pekerjaan \\
\hline P1 & 29 tahun & P1 A0 Ah1 & D3 & IRT \\
P2 & 29 tahun & P1 A0 Ah1 & S1 & Guru \\
P3 & 37 tahun & P2 A0 Ah2 & SLTA & IRT \\
P4 & 30 tahun & P1 A1 Ah1 & S1 & Guru \\
P5 & 30 tahun & P1 A0 Ah1 & SLTA & Wiraswasta \\
P6 & 30 tahun & P1 A0 Ah1 & S1 & Karyawan Swasta \\
P7 & 35 tahun & P3 A0 Ah1 & SLTA & IRT \\
\hline
\end{tabular}

Sumber: Data primer, 2018

lumnya). Berikut ini karakteristik partisipan digambarkan melalui tabel rekapitulasi karakteristik partisipan untuk memudahkan pembaca memahami karakteristik partisipan dalam penelitian ini (Tabel 1).

Dalam penelitian ini didapatkan partisipan sebanyak tujuh orang dan seluruh partisipan dalam penelitian ini sudah dalam kriteria dalam penelitian. Berdasarkan Tabel 1 dapat diketahui bahwa partisipan mempunyai pekerjaan yang beraneka ragam dan sebagian besar partisipan merupakan ibu rumah tangga. Pendidikan paling terendah dari partisipa adalah SLTA dan yang paling tertinggi adalah sarjana. Usia partisipam dalam penelitian ini mulai dari 29 tahun sapai 37 tahun.

Setelah membaca hasil transkrip wawancara berulang-ulang dan melihat catatan lapangan dari masing-masing partisipan, peneliti mengidentifikasi kutipan kata dan pernyataan yang bermakna sesuai dengan yang diteliti.

\section{Pengetahuan Partisipan terhadap Perawatan Masa Nifas}

Robbins (2008), mengemukakan bahwa ketika seorang individu melihat sebuah target dan berusaha untuk menginterpretasikan apa yang ia lihat, interpretasi itu sangat dipengaruhi oleh berbagai karakteristik pribadi dari pembuat persepsi tersebut, seperti sikap, kepribadian, motif, minat, pengalaman-pengalaman masa lalu dan harapan-harapan seseorang. Pengetahuan akan akses informasi bisa memberikan preferensi atau pengetahuan yang jauh lebih banyak kepada perempuan dalam proses memahami dirinya. Pengetahuan mereka akan tentang persiapan masa nifas akan membuat mereka mengakses berbagai cara agar mereka siap dalam menghadapi masa nifas.

Dalam kenyataannya mayoritas partisipan tidak mencari informasi persiapan dirinya untuk menghadapi masa nifas. Mereka hanya menerima informasi yang didapatkan dari tenaga kesehatan setelah melahirkan dan akan pulang kerumah. Partisipan juga mencari informasiketika ada masalah dan mendapatkan sumber informasi tersebut tanpa mengetahui kebenarannya sehingga pemahaman partisipan terhadap perawatan masa nifas ini hanya sebatas pengetahuan yang selama ini didapat dari media sosial sehingga jika mendapatkan saran dari keluarga dan masyarakat langsung diterima 
mentah-mentah tanpa mengkaji apakah informasi tersebuat benar atau tidak dan membahayakan bagi dirinya atau tidak.

Seperti yang diungkapkan partisipan sebagai berikut:

“... sebelum pulang diajarkan harus sering-sering mengganti pembalut, menjaga kebersihan ..." (P1)

“... disarankan untuk memberikan ASI eksklusif dan alhamdulillah ini ASI saya lancar jadi bisa menyusui terus........" (P2)

Berdasarkan dari pengetahuan dan informasi yang didapat dapat disimpulkan bahwa dari tujuh partisipan yang diwawancara hanya satu partisipan yang melakukan persiapan untuk menghadapi masa nifas. Persiapan yang dilakukan partisipan ini adalah mengikuti kelas ibu hamil secara rutin mulai dari masa kehamilan sampai masa nifas ini. Partisipan yang lain hanya melakukan pemeriksaan ANC secara rutin dan mengakses informasi dari internet.

Berikut ungkapan partisipan yang melakukan persiapan untuk menghadapi masa nifas:

“... di tempat saya periksa selama hamil ada kelas ibu hamil dan saya ikut sampai sekarang ini. Di sana banyak sekali informasi yang saya dapatkan seputar bagaimana persiapan menjadi seorang ibu ..." (P4)

“... hanya baca-baca aja di internet ...” (P5)

Persiapan yang dilakukan secara matang akan sangat berbeda dengan partisipan yang tidak melakukan persiapan secara matang. Jika partisipan yang melakukan persiapan secara matang partisipan tersebut berani mengatakan tidak kepada orang lain jika informasi yang disampaikannya itu salah. Tetapi jika partisipan yang tidak memiliki persiapan yang matang maka mereka akan menerima semua informasi yang didapat tanpa menyeleksi dan pada akhirnya akan merugikan dirinya sendiri. Seperti yang dikatakan oleh partisipan tersebut:

“... setiap ada masalah yang saya hadapi sudah langsung tanggap apa yang harus dilakukan karena dari dulu sampai sekarang saya mengikuti kelas ibu hamil yang sejak dulu saya ikuti ...." (P4)

“... sebenarnya ya takut tapi bismillah saja lah ..." (P5)

\section{Budaya di Masyarakat dan Pengaruhnya terhadap Perawatan Masa Nifas}

Setiap partisipan memiliki cara pandang masing-masing terhadap budaya yang ada di sekitar tempat tinggal mereka khususnya budaya yang berkaitan dengan perawatan dalam masa nifas. Sumber informasi yang diperoleh partisipan berkaitan dengan budaya yang ada di sekitar yang berpengaruh terhadap perawatan masa nifas berasal dari keluarga partisipan.

Seperti yang diunkapkan oleh partisipan sebagai berikut:

“...selama ini hanya dikasih wejanganwejangan dari orang yang menjenguk, selama masih dalam batas wajar saya lakukan. Tapi kalau tidak masuk akal tidak saya lakukan..."(P3)

“... kadang kalau dikasih tau tetangga tapi menurut saya tidak masuk malah saya kasih tau yang sebenarnya seperti apa sesuai dengan ilmu yang saya dapat selama saya ikut kelas ibu hamil ..." (P4) 
“... saya tidak begitu merasakan secara langsung adanya adat budaya yang ada dimasyarakat yang mengatur selama saya masa nifas ini ..." (P6)

Dalam penelitian ini seluruh partisipan satu atap dengan mertua sehingga pengaruh keluarga baik suami maupun mertua sangat berpengaruh terhadap perawatan masa nifas. Sehingga kepercayaan budaya yang diyakini oleh mertua partisipan diterapkan dalam kehidupan sehari-hari terutama dalam perawatan masa nifas ini.

Berikut merupakan uangkapan dari partisipan:

“... manut saja Mbak sama orang tua, toh orang tua memberikan saran seperti itu untuk yang terbaik buat anaknya ..." (P3)

“... saya merasa mertua saya kolot banget, untung aja saya ikut kelas ibu hamil dan ikut group-group gitu jadi ada tempat sharing jadinya misal mertua saya ngasih saran yang tidak masuk akal langsung saya tolak hehehe ...." (P4)

Apabila ibu nifas sudah memiliki persiapan yang cukup untuk menghadapi masa nifas ketika mereka masih berada pada masa kehamilan setidaknya partisipan bisa memilih informasi yang tepat untuk dirinya ketika pada masa nifas seperti ini banyak sekali informasi dan intervensi yang diterima baik dari keluarga maupun orang sekitar. Sebenarnya intervensi yang dierikan keluarga terhadap dirinya merupakan suatu upaya untuk menjaga kesehatan dan kebaikan partisipan. Untuk setiap intervensi yang diberikan pada partisipan selama masa nifas ini bertujuan untuk menjaga kesehatan partisipan seperti yang dikemukakan Sibley, dkk (2009). Salah satu contohnya adalah partisipan ada yang tidak boleh mandi terlalu sore, alasan ini mungkin jika mandi terlalu sore akan kedinginan dan akan menyebabkan flu sehingga jika ibu flu akan menularkan ke anaknya.

Seperti yang dikatakan oleh partisipan berikut ini:

“... tidak boleh mandi terlalu sore nanti anaknya pilek ..." (P6)

“... di baju bayi dikasih peniti yang ada benglenya biar tidak ada lelembut yang mengganggu ..." (P7)

Budaya yang ada di sekitar kita sebenarnya bukan untuk ditentang atau di hilangkan tetapi kita dituntut untuk cerdas dalam menyikapi budaya yang ada di sekitar kita. Karena apabila kita kaji setiap budaya yang ada di sekitar tentunya memiliki tujuan yang baik terutama dalam budaya dalam perawatan masa nifas ini memiliki tujuan yang baik yaitu untuk menjaga kesehatan, kita harus pintar-pintar untuk menyeleksi informasi dan intervensi yang baik untuk diri kita.

\section{Dukungan Keluarga dalam Perawatan Masa Nifas}

Selama masa nifas seluruh partisipan merasakan keluarga dan suami sangat membantu dan mensuport dalam perawatan masa nifas. Sehingga partisipan tidak merasa sendiri dan merasa diperhatikan oleh keluarga. Pendampingan yang secara utuh dari keluarga yang membuat partisipan merasa nyaman dan merasa tidak mengalami kesulitan selama masa nifas, baik perawatan untuk dirinya maupun perawatan terhadap anaknya hal ini sesuai dengan 
penelitian (Wahyuni, 2017). Berikut ungkapan dari partisipan:

“... keluarga sangat membantu saya selama proses setelah melahirkan ini ..." (P1)

“... suami dan mertua saya membantu saya, terutama di awal masa nifas ini dimana saya masih sangat butuh bantuan orang lain ..." (P2)

Perawatan selama masa nifas ini selalu dibantu keluarga sehingga apapun yang diketahui oleh keluarga dalam perawatan masa nifas diterapkan kepada partisipan termasuk pengalaman orang tua dahulu ketika mereka dirawat oleh keluarganya. Berikut ungkapan dari partisipan:

“... kalau tidur kakinya tidak boleh ditekuk, nanti bengkok karena orang yang setelah meahirkan tulangnya menjadi muda ..." (P3)

“... harus makan bawang putih sebanyakbanyaknya agar darah kotor keluar semua..." (P3)

Kurangnya pengetahuan yang dimiliki partisipan terhadap perawatan masa nifas maka partisipan tidak mengetahui apakah intervensi yang diberikan keluarga benar atau tidak. Sehingga partisipan tidak dapat menolak apa yang diberikan oleh keluarganya selama perawatan masa nifas ini.

\section{Kesimpulan}

Partisipan paham terkait dengan masa nifas. Kurangnya persiapan partisipan untuk menghadapi masa nifas. Dalam perawatan masa nifas masih ada unsur budaya yang diterapkan dalam keluarga dan partisipan tidak dapat menolak apa yang diintervensikan kepada dirinya. Keluarga dan suami sangat berperan dalam perawatan masa nifas. Partisipan selalu dibantu oleh keluarga dan suami selama masa nifas.

\section{Ucapan Terimakasih}

Peneliti mengucapkan terima kasih kepada LPPM Universitas 'Aisyiyah Yogyakarta yang telah memberikan dana sehingga penelitian ini dapat terlaksana.[]

\section{Daftar Pustaka}

Arikunto, S. (2013). Prosedur Penelitian Suatu Pendekatan Praktik. Jakarta: Rineka Cipta.

Iqbal, W. M., Nurul, C., \& Iga, M. (2012). IImu sosial budaya dasar kebidanan. Jakarta: EGC Penerbit Buku Kedokteran.

Nursalam. (2008). Konsep dan penerapan metodologi penelitian ilmu keperawatan. Jakarta: Salemba Medika.

Pusdatin. (2018). Profil Kesehatan 2018. Diambil dari https://pusdatin.kemkes.go.id/resources/do wnload/pusdatin/profil-kesehatanindonesia/PROFIL_KESEHATAN_2018_1.pdf

Rahayu, I. S., Mudatsir, M., \& Hasballah, K. (2017). Faktor Budaya dalam Perawatan Ibu Nifas. Jurnal IImu Keperawatan, 5(1), 36-49. Diambil dari http://jurnal.unsyiah.ac.id/ JIK/article/view/8761

Sibley, L. M., Hruschka, D., Kalim, N., Khan, J., Paul, M., Edmonds, J. K., \& Koblinsky, M. A. (2009). Cultural theories of postpartum bleeding in Matlab, Bangladesh: Implications for com munity health intervention. Journal of Health, Population and Nutrition, 27(3), 379-390. https://doi.org/10.3329/jhpn.v27i3.3380 
Suryawati, C. (2017). Faktor Sosial Budaya dalam Praktik Perawatan Kehamilan, Persalinan, dan Pasca Persalinan (Studi di Kecamatan Bangsri Kabupaten Jepara). Jurnal Promosi Kesehatan Indonesia, 2(1), 21-31.

Wahyuni, S. (2017). Hubungan dukungan sosial suami terhadap pola pantang makan ibu nifas di wilayah kerja Puskesmas Karangdowo Klaten. Involusi: Jurnal Ilmu
Kebidanan, 7(1), 51-57. Diambil dari http://jurnal.stikesmukla.ac.id/index.php/inv olusi/article/view/282

Yuliani, F. (2011). Perilaku Pantangan Makanan pada Ibu Nifas di BPS "A" Balongtani Jabon Sidoarjo. Hospital Majapahit, 3(1), 54-73. Diambil dari http://ejournal.stikesmajapahit. ac.id/index.php/HM/article/view/36 